\section{How to evaluate journal impact factors}

Sir - Journal impact factors, published annually by the Institute of Scientific Information (ISI) in two Journal Citation Reports (JCR) editions (science and social science), are a well known — though not uncontested $^{1,2}$ - means of evaluating and comparing the scientific impact of journals. A major disadvantage of the JCR is the limited number of evaluated journals. For example, the 1996 JCR on CD-ROM (science edition) lists 4,779 journals, roughly half of them with biomedical orientation.

In contrast, about 4,000 journals are continuously indexed in Medline, nearly 3,500 in Embase and at least 4,600 in Biosis, making a total (without duplicate titles) of about 7,000 unique journals in these three biomedical databases (data retrieved from Serline).

There is, however, an easy way to construct impact factors also for journals not included in the JCR. Online database searches can be carried out to determine the number of published articles in a given journal and the number of citations to that journal, according to ISI's definition of a journal's impact factor (number of citations in year $\mathrm{X}$ to papers published in the journal in question in years $\mathrm{X}-1$ and $\mathrm{X}-2$, divided by the number of counted articles).

The table shows constructed impact factors (CIF) for several biomedical journals not included in the JCR 1996 science edition (No. 1-11). In addition, to confirm the reliability of the method, the constructed as well as the JCR-derived impact factors (JCR-IF) are shown for a couple of journals included by JCR (No. 12-17). All online searching was carried out at the German host DIMDI (Deutsches

Institut für Medizinische Dokumentation und Information). Numbers of articles published in 1994 and 1995 were retrieved by searching the databases Medline, Cancerlit, Healthstar, Embase, Biosis and Scisearch simultaneously (DIMDI's 'superbase' modus), followed by elimination of duplicate articles using the 'check duplicates' command of DIMDI's retrieval language. Editorials, letters, news and meeting reports were excluded from searches because they are not subject to ISI's citation analyses ${ }^{3}$. Numbers of citations were retrieved from ISI's database Scisearch which - in addition to bibliographic data - contains all the references cited in the indexed articles, whether the cited journal is being indexed in Scisearch or not.

The slight differences between constructed and JCR-derived impact factors may be due to the following: (i) for retrieval of published articles the document types 'article', 'journal article' and 'review' were used, which may have a wider definition in non-ISI databases, thus leading to higher article counts (and lower CIFs) than the more restrictive use of the term 'research article' seen in JCR 4; and (ii) Scisearch comprises more journals than JCR (personal communication from ISI) which may lead to higher citations.

Impact factors can only give some hints with respect to the importance of a journal in its field. Nevertheless, because there is permanent pressure on scientists to prove the impact of their work and to publish in journals with measurable impact factors, the method described might also be helpful in evaluating those journals not listed in JCR.

\title{
Johannes Stegmann
}

University Clinic Benjamin Franklin,

Free University Berlin,

12200 Berlin,

Germany

e-mail:stegmann@ukbf.fu-berlin.de

\section{Constructed impact factors for journals not in JCR}

\begin{tabular}{|c|c|c|c|c|c|}
\hline No. & Journal & $\begin{array}{c}\text { Articles published } \\
1994+1995\end{array}$ & $\begin{array}{l}\text { Citations } \\
1996\end{array}$ & CIF & JCR-IF \\
\hline 1 & Advances in Neurology & 122 & 74 & 0.607 & - \\
\hline 2 & Advances in Pharmacology & 180 & 434 & 2.411 & - \\
\hline 3 & American Journal of Dentistry & 143 & 203 & 1.420 & - \\
\hline 4 & Annals of Clinical Psychiatry & 68 & 47 & 0.691 & - \\
\hline 5 & Brain Topography & 59 & 55 & 0.932 & - \\
\hline 6 & British Journal of Clinical Psychology & 111 & 35 & 0.315 & - \\
\hline 7 & Current Topics in Pathology & 35 & 27 & 0.771 & - \\
\hline 8 & International Dental Journal & 124 & 95 & 0.766 & - \\
\hline 9 & International Journal of Health Services & 89 & 21 & 0.236 & - \\
\hline 10 & Morbidity and Mortality Weekly Report & 774 & 147 & 0.190 & - \\
\hline 11 & Stereotactic and Functional Neurosurgery & 171 & 62 & 0.363 & 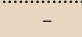 \\
\hline 12 & Abdominal Imaging & 287 & 202 & 0.704 & 0.733 \\
\hline 13 & Cellular Immunology & 573 & 1,243 & 2.169 & 2.142 \\
\hline 14 & International Journal of Developmental Biology & 201 & 352 & 1.751 & 1.702 \\
\hline 15 & Molecular Medicine & 81 & 304 & 3.753 & 3.972 \\
\hline 16 & Nature & 1,994 & 54,024 & 27.093 & 28.417 \\
\hline 17 & Transplant International & 165 & 238 & 1.442 & 1.522 \\
\hline
\end{tabular}

Moed, H.F \& van Leeuwen, Th. N. Nature 381, 186 (1996).

2. Opthof, T. Cardiovasc. Res. 33, 1-7 (1997).

3. Journal Citation Reports (Science ed.) 1996 on CD-ROM. Citation and Article Counts.

4. Journal Citation Reports (Science ed.) 1996 on CD-ROM. Using the JCR Wisely.

\section{Standards for}

\section{safety cabinets}

Sir - In the past few years, protection from potential airborne hazards associated with handling microbiological agents in the laboratory has owed much to the improvement in containment performance of microbiological safety cabinet installations after the smallpox outbreak in the United Kingdom in 1978.

A new European safety cabinet standard is now being proposed to cover the whole field of biotechnology. Early in the discussions for the standard, it was agreed that UK standard BS 5726 (1992) would form the basis of the European Union (EU) standard.

It has recently been suggested, however, that type testing and the measurement of safety cabinet airflows, together with some site evaluation (but no measured validation) is sufficient to guarantee worker protection without the need for on-site containment tests.

In my opinion, this will be a retrograde and dangerous step. A recent survey of test results over 12 months from one major independent UK test house showed that 37 class II safety cabinets (all with adequate type test certification and including 18 new installations) failed to meet the BS 5726 operator protection factor requirements.

In all cases where containment failed, problems of the cabinet or the environment were identified and remedial action taken. Without on-site containment tests, potentially dangerous equipment would have been in service.

The new performance standard for microbiological safety cabinets is being developed under the banner of biotechnology, but it is likely that its use will extend to all other areas where microbiological material is being handled, particularly when related national standards in EU countries are withdrawn under the EU standardization rules.

It is vital that, in the context of the proposed safety cabinet standard, testing for containment both at commissioning and during routine maintenance remains a fundamental requirement.

\section{Raymond P. Clark}

Cranfield Biomedical Centre,

Institute of BioScience and Technology,

Cranfield University,

Cranfield, Bedfordshire MK43 OAL, UK

e-mail:ray@medi.demon.co.uk 